\title{
Pengolahan Sampah Rumah Tangga Menjadi Kompos di Kelurahan Tuah Madani Kecamatan Tampan Kota Pekanbaru
}

\author{
Latifa Siswati*1, Rini Nizar $^{2}$, Anto Ariyanto ${ }^{3}$ \\ 1,2,3Program Studi Agribisnis, Fakultas Pertanian, Universitas Lancang Kuning \\ *E-mail: latifasiswati@unilak.ac.id
}

\begin{abstract}
Tuah Madani Subdistrict Tampan District already has a Waste Bank, but to process organic waste into compost, the Garbage Bank cadres in each RW still do not have this knowledge. The Unilak Community Service Team has the required knowledge, and through this activity a transfer of knowledge is carried out, so that the Garbage Bank Cadres will more optimally manage the waste that has been collected in the Waste Banks of each RW. The method of activities that will be given to the community is, awareness, counseling, demonstration, and evaluation. Awareness is intended to give awareness to the Garbage Bank Cadre that managing waste into compost will have a positive impact on the environment. Counseling aims to provide knowledge to the community so that they are more sensitive to their environment, so that the environment will provide results that benefit their families. Demonstration aims to provide knowledge directly, both through picture shows, and direct practice making compost from household waste. And an evaluation is carried out to determine the level of knowledge of partners before and after the activity, and to find out the success of the activity.
\end{abstract}

Keywords: household waste, compost, waste bank

\begin{abstract}
Abstrak
Kelurahan Tuah Madani Kecamatan Tampan sudah memiliki Bank Sampah, tetapi untuk mengolah sampah organik menjadi kompos, kader Bank Sampah setiap RW masih belum memiliki pengetahuan tersebut. Tim Pengabdian Masyarakat Unilak memiliki pengetahuan yang dibutuhkan tersebut, dan melalui kegiatan ini dilakukan transfer pengetahuan, sehingga Kader Bank Sampah akan lebih optimal mengelola sampah yang sudah terkumpul di Bank Sampah masing-masing RW.Metode kegiatan yang akan diberikan kepada masyarakat adalah, penyadaran, penyuluhan, demonstrasi, dan evaluasi. Penyadaran ditujukan untuk memberikan kesadaran pada Kader Bank Sampah bahwa pengelolaan sampah menjadi kompos akan berdampak positif terhadap lingkungannya. Penyuluhan bertujuan untuk memberikan pengetahuan kepada masyarakat agar mereka lebih peka terhadap lingkungannya, sehingga lingkungan akan memberikan hasil yang bermanfaat bagi keluarganya. Demontrasi bertujuan untuk memberikan pengetahuan secara langsung, baik melalui tayangan gambar, dan praktek langsung membuat kompos dari sampah rumahtangga. Dan evaluasi dilakukan untuk mengetahui tingkat pengetahuan mitra sebelum dan sesudah kegiatan, dan untuk mengetahui keberhasilan kegiatan tersebut.
\end{abstract}

Kata kunci: Sampah rumah tangga, Kompos, Bank sampah

\section{PENDAHULUAN}

Hingga Hingga saat ini, permasalahan kesehatan yang berkaitan dengan gizi masih perlu diwaspadai, terutama bagi negara berkembang termasuk Indonesia (Astuti, Megawati, \& CMS, 2018). Karena, permasalahan kesehatan yang berkaitan dengan gizi merupakan prediktor buruknya kualitas sumber daya manusia yang selanjutnya akan berpengaruh pada pengembangan potensi bangsa (UNICEF, 2013).

Kelurahan Tuah Madani Kecamatan Tampan adalah salah satu Kelurahan yang sudah memiliki kelompok penggiat Bank Sampah. Permasalahan yang dihadapi oleh Kader Bank Sampah adalah minimnya pengetahuan mereka dalam mengelola sampah organik untuk dijadikan kompos, sedangkan bahan untuk pembuat kompos tersedia di sekitar rumah dan dihasilkan dari dapur rumah.

Universitas Lancang Kuning melalui Tim Pengabdian Masyarakat memiliki pengetahuan untuk mengolah sampah rumah tangga menjadi kompos. Sehingga kegiatan ini dijadikan sebagai 
sarana untuk mentransfer pengetahuan yang dimiliki ke khalayak umum yang membutuhkan. Berdasarkan kegiatan yang dilakukan oleh (Sulistyorini, 2005) dilaporkan bahwa transfer teknologi kepada masyarakat dapat meningkatkan pengetahuan mereka dalam mengolah sampah menjadi lebih berguna. Kegiatan yang dilakukan oleh (Suprapto, Ali, dan Nuryadin, 2017) menghasilkan kesadaran masyarakat yang meningkat dalam mengelola lingkungannya dari sampah rumah tangga menjadi kompos dan kompos cair. Penelitian Rahman A, dan Afriyanto (2015) menyatakan bahwa pengetahuan penduduk perkotaan tentang sampah cukup baik, tetapi sikap dan tindakan masyarakat tentang pengelolaan sampah rumah tangga masih kurang. (Sinartani, 2011) melaporkan bahwa sampah organik yang dihasilkan di daerah perkotaan bersifat biodgradable (dapat terurai), sehingga dapat dimanfaatkan, proses penguraiannya biasanya memanfaatkan mikroorganisme pengurai seperti EM-4 dan aktifator lainnya ataupun mikroorganisme pengurai yang ada di dalam tanah.

Pembuatan kompos yang berasal dari sampah dapat digunakan untuk tanaman hias dengan perbandingan 1:1, sedangkan untuk tanaman sayur penambahan kompos yang dihasilkan dari sampah harus diikuti dengan penambahan pupuk anorganik. Pernyataan diatas menurut Handayani S, Ismillayli N, Kamal S.R, dan Hadi S (2018) bahwa pengelolahan limbah organik rumah tangga di Desa Leubak Kecamatan Narmada, dengan proses fermentasi dengan EM-4 menghasilkan pupuk organik yang dapat dimanfaatkan untuk budidaya sayuran di pekarangan. Pembuatan kompos dengan penambahan serpihan kayu dapat meningkatkan $\mathrm{C} / \mathrm{N}$ ratio dan meningkatkan $\mathrm{pH}$ kompos hal ini disebabkan karena proses pengomposan berada pada kondisi aerobic (Ruslinda dan Aziz, 2004).

Kelurahan Tuah Madani merupakan salah satu kelurahan di Kecamatan Tampan kota Pekanbaru, lokasi kelurahan ini berbatasan langsung dengan Kabupaten Kampar. Setiap hari banyak sekali sampah yang dihasilkan oleh setiap rumah tangga tetapi selama ini belum dimanfaatkan oleh masyarakat dibuang ketempat sampah yang kadang -kadang tidak diangkat setiap harinya sehingga menimbulkan bau dan kadang sudah ada ulatnya. Maka dengan adanya kegiatan yang pelatihan dan penyuluhan pengolahan sampah organik rumah tangga menjadi pupuk kompos.

Sampah organik sangat melimpah di lingkungan rumah maupun yang berasal dari dalam rumah, tetapi kader Bank Sampah belum mampu mengelola sampah organik ini menjadi kompos yang memiliki nilai tersendiri terhadap lingkungan.

Pengolahan smapah rumah tangga menjadi kompos membutuhkan Bioaktifator agar proses pengomposan lebih cepat, tetapi kader Bank Sampah belum paham bagaiman cara menggunakan bioaktifator tersebut, sehingga perlu adanya suatu pengenalan dan demonstrasi menggunakan bioaktifator tersebut agar berfungsi dalam mengurai sampah organik.

\section{METODE}

Kegiatan pengabdian masyarakat ini akan mencapai tujuannya dengan beberapa cara yang akan dilaksanakan di lokasi kegiatan, antara lain:

a. Penyadaran : kegiatan ini merupakan kegiatan yang sangat penting, karena sebelum mitra itu menyadari akan manfaat kompos, dan manfaat kompos, maka kegiatan ini tidak akan berhasil.

b. Penyuluhan : kegiatan ini dilakukan setelah mitra merasa mereka membtuhkan ilmu yang akan diperoleh untuk memanfaatkan sampah organik menjadi kompos.

c. Demonstrasi : kegiatan ini dilakukan untuk menunjukkan kepada mitra tentang contoh contoh pembuatan kompos dan sampah yang dihasilkan dari pekarangan maupun dari dapur rumah.

d. Evaluasi : kegiatan ini dilakukan dengan menyebarkan kuesioner sebelum dan sesudah kegiatan dilakukan. 


\section{HASIL DAN PEMBAHASAN}

Pengabdian pada masyarakat dilaksanakan pada tanggal 5 Desmber 2019, lokasi kegiatan di gedung pertemuan Kelurahan Tuah Madani Kecamatan Tampan, dihadiri oleh 30 peserta. Kegiatan dibuka oleh Lurah Kelurahan Tuah madani bapak Peri Susanto, SE., dan kegiatan penyuluhan ini dihadiri oleh muspida Kecamatan Tampan ..

Peserta yang mengikuti kegiatan ini sangat antusias terutama pada saat kegiatan demonstrasi, seluruh peserta turut serta dalam mengolah sampah yang sudah dibawa untuk dijadikan kompos.
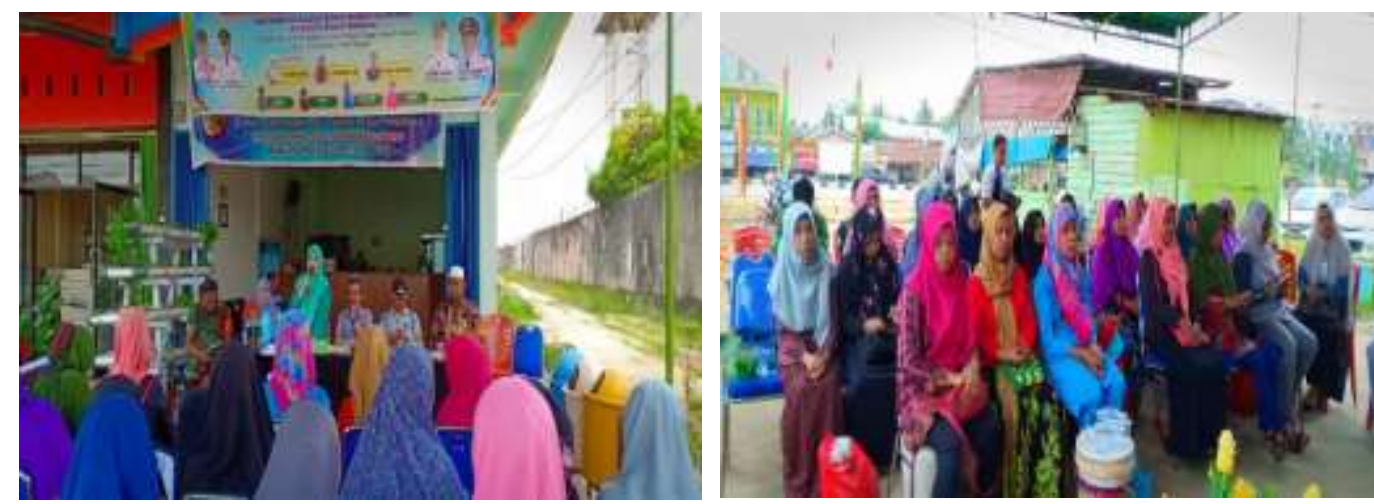

Gambar 1. Peserta pelatihan pegolahan sampah rumah tangga menjadi kompos

Pada saat kegiatan kendala adalah tidak adanya alat perajang sampah rumah tangga yaitu mesin pemotong sampah untuk dijadikan kompos, sehingga bahan organik yang akan dikomposkan ukurannya masih besar dan kasar, hal ini dapat menghambat kecepatan pengomposan. Bahan organik yang digunakan dalam pembuatan kompos harus kecil dan homogen, karena semakin kecil ukuran bahan yang digunakan maka proses pengomposan akan semakin cepat, yang utama adalah aerasi dalam tumpukan bahan kompos harus terjaga, dan penambahan starter bahan organik dilakukan setiap hari dengan penambahan mikroba yang akan membantu mempercepat pengomposan Sulistyorini (2005).

Pengabdian masyarakat ini Tim menggunakan bio aktifator EM 4, mudah didapat dan peserta dapat membeli di toko pertanian. Berdasarkan laporan Darmawati (2015), bahwa EM 4 merupakan salah satu bio aktifator yang berpengaruh terhadap pengomposan limbah sayur dan dedaunan. Widiyaningrum, dan Lisdiana (2004) melaporkan bahwa EM 4 yang digunakan dalam pengomposan menghasilkan penyusutan bahan organik yang paling tinggi, dibandingkan dengan bio aktifator yang lain.

Bahan organik yang digunakan salah satunya adalah serbuk gergaji , dimana diketahui bahwa serbuk gergaji merupakan bahan organik yang lama proses penguraiannya, tetapi menghasilkan aerasi yang baik di lingkungan pengomposan, dan menyebabkan kelembaban menjadi rendah. Seperti yang dilaporkan oleh Ruslinda dan Aziz, (2004), bahwa penambahan serpihan kayu menyebabkan suhu dan kelembaban menjadi lebih rendah sehingga kondisi menjadi aerob, dan hal ini tidak dapat memenuhi kelembaban yang diharapkan yaitu di atas 50\% dan $\mathrm{pH}$ tidak memenuhi persyaratan pengomposan.

Untuk starternya bahan kompos yang digunakan pada kegiatan ini mengunakan pupuk kandang Anjuran pembuatan kompos starter digunakan baik itu berupa pupuk kandang atau kompos yang sudah jadi, agar proses pengomposan lebih cepat terlaksana, seperti yang dilaporkan oleh Sahwan dan Wahyono, (2011), kompos matang digunakan untuk menstimulir kerja komposter yang digunakan dalam menguraikan bahan organik yang dijadikan bahan kompos. Kompos yang baik akan mengalami penyusutan hampir 50\% dari berat semula, dan 
tetap lembab (Setyaningsih et al., 2017)

Hasil evaluasi kuesioner sebelum dan sesudah kegiatan ditampilkan pada Tabel berikut:

Tabel 1. Rekap kuesioner sebelum kegiatan

\begin{tabular}{lccc}
\hline \multirow{2}{*}{ Kuesioner } & \multicolumn{3}{c}{ Jawaban (\%) } \\
\cline { 2 - 4 } & Sebelum & Sesudah & peningkatan \\
\hline Mengetahui limbah organik rumah tangga & 85.71 & 100 & 14,29 \\
Pelatihan sampah rumah tangga & 42.86 & 100 & 57,14 \\
$\begin{array}{l}\text { Bahan untuk membuat kompos dari } \\
\text { sampah rumah tangga }\end{array}$ & 50.00 & 100 & 50,00 \\
$\begin{array}{l}\text { Alat yang digunakan untuk membuat } \\
\text { kompos dari sampah rumah tangga }\end{array}$ & 39.28 & 100 & 60,72 \\
$\begin{array}{l}\text { Cara membuat kompos dari sampah } \\
\text { rumah tangga }\end{array}$ & 32.14 & 100 & 67,86 \\
$\begin{array}{l}\text { Memanfaatkan kompos dari sampah } \\
\text { rumah tangga }\end{array}$ & 28.57 & 100 & 71,43 \\
$\begin{array}{l}\text { Menyukai kompos organic sebagai pupuk } \\
\text { Berminat menjadi pengusaha kompos }\end{array}$ & 82.14 & 100 & 17,86 \\
$\begin{array}{l}\text { Pernah membeli pupuk kompos } \\
\text { Mengetahui lama proses kompos dapat }\end{array}$ & 92.86 & 100 & 7,14 \\
dipakai & 82.86 & 100 & 57,14 \\
\end{tabular}

Peserta pelatihan pernah mengikuti pelatihan pembuatan kompos sebanyak 42,86 \% sedangkan yang belum mengikuti pelatihan pembuatan kompos dari sampah rumah tangga 57,14 $\%$, bahan pembuat kompos dari sampah rumah tangga peserta mengetahui 50\%. Alat dan cara membuat kompos masih banyak yang belum mengetahui 60,72 \% dan 67,86 \% dan manfaat sampah rumah tangga untuk dijadikan kompos juga belum banyak diketahui hanya $28,57 \%$. Sebagian besar $82,14 \%$ peserta menyukai pupuk organic/kompos, hampir semua peserta $92,86 \%$ berminat menjadi penguasaha kompos. Pengetahuan peserta tentang pupuk organik dan anorganik juga sangat minim sekali, sehingga kegiatan yang dilakukan perlu dilanjutkan dengan kegiatan berikutnya.

Sampah yang ada disekitar rumah atau sampah rumah tangga perlu penanganan yang tuntas agar lingkungan terjaga dan asri, kegiatan yang incidental belum dapat menuntaskan masalah yang dihadapi, kegiatan ini baru dapat meningkatkan pengetahuan peserta dalam mengolah sampah menjadi kompos. Sebelum mendapat pelatihan peserta belum mengetahui adanya bioaktivator untuk membantu mempercepat proses pengomposan.

Pengabdian pada masyarakat yang dilakukan meningkatkan pengetahuan peserta seperti yang tercantum pada Tabel 1. Peningkatan yang terjadi berkisar antara 7,14\% - 71,43\%, peningkatan yang beragam sesuai dengan pengetahuan peserta dan keseriusan peserta dalam menyimak penjelasan yang diberikan. Menurut Suprapto et al., (2017), kurangnya pengetahuan masyarakat tentang penangan limbah menjadi sesuatu yang bermanfaat perlu sosialisasi yang berkesinambungan. Sedangkan menurut Suhastyo, dan Asriyanti, (2017) terjadi peningkatan pengetahuan peserta dan peningkatan ketrampilan dalam memanfaatkan bahan organik menjadi kompos.

Kelurahan Tuah Madani juga telah terjadi peningkatan pengetahuan masyarakat tentang pembuatan kompos dari sampah rumah tangga. Sesuai dengan Siswati,dkk (2019) kegiatan pelatihan dapat meningkatkan pengetahuan dan pemahaman peserta pelatihan berkisar antara 4- 95 \% di Kelurahan Labuh Baru Timur. 


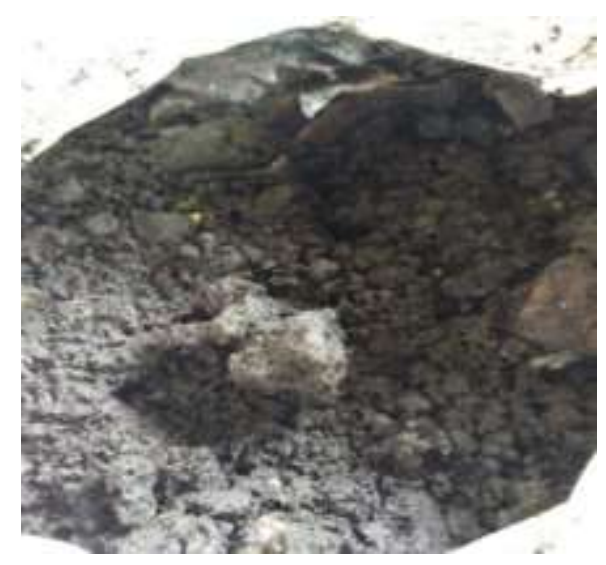

Gambar 2. Pupuk kompos dari sampah rumah tangga

\section{KESIMPULAN}

Kegiatan pengabdian masyarakat ini dapat ditarik kesimpulan bahwa telah terjadi peningkatan pengetahuan, pemahaman, dan ketrampilan peserta berkisar antara 7,14\%- 71,43 $\%$. Proses pengomposan sangat tergantung dari ukuran bahan organik yang dijadikan bahan untuk kompos, semakin kecil ukuran potongan bahan organik maka proses pengomposan akan semakin cepat. Bio aktifator yang digunakan berperan dalam mempercepat proses pengomposan, selain itu kehomogenan bahan juga menjadi pertimbangan dalam pengomposan.

\section{UCAPAN TERIMA KASIH}

Ucapan terimakasih ditujukan kepada Lurah Tuah Madani yang telah memberikan kesempatan untuk melakukan kegiatan pengabdian di wilayah administratifnya, dan terimakasih diucapkan kepada pimpinan Unilak dan fakultas Pertanian yang telah memberikan bantuan finansial dalam melaksanakan kegiatan ini.

\section{DAFTAR PUSTAKA}

Agus Rahman., \& Afriyanto. 2015. Karakteristik Penanganan Sampah Rumah tangga Di Kota Bengkulu. Jurnal Kesehatan Masyarakat Andalas. Voume 1 (1)

Darmawati. 2015. Efektivitas Berbagai Bioaktivator Terhadap Pembentukan Kompos Dari Limbah Sayur Dan Daun. J. Dinamika, XXX(2), 93-100.

Ruslinda, Y., \& Aziz, R. (2004). Pengaruh Penambahan Serpihan Kayu Terhadap Kualitas Kompos Sampah Organik Sejenis Dalam Komposter Rumah Tangga. J.Teknik Lingkungan, 14(1), 13-22.

Sahwan, F. L., dan Wahyono, S. 2011. Kualitas Kompos Sampah Rumah Tangga Yang Dibuat Dengan Menggunakan "Komposter" Aerobik. J. Teknik Lingkungan, 12(3), 233-240.

Septiani Handayani, Nurul ismillayli, Siti Raudhatul Kamal, Surya hadi. 2018. Pengolahan Mandiri Limbah Organik Rumah Tangga Untuk Mendukung Pertanian Organik lahan Sempit. Jurnal Pijar MIPA. Volume 3 (2)

Sinartani. (2011). Pupuk Organik dari Limbah Organik Sampah Rumah Tangga. Agroinovasi, $3(3417)$.

Siswati, L., Ningsih, A. T. R., \& Jeniwardi, J. (2019). Pengolahan Sampah Rumah Tangga Menjadi Kompos Di Kelurahan Labuh Baru Timur Pekanbaru. Prosiding Konferensi Nasional 
Pengabdian Kepada Masyarakat dan Corporate Social Responsibility (PKM-CSR), 2, 660-665.

Suhastyo, A. A., Agroteknologi, P. S., Banjarnegara, P., \& Tengah, J. (2017). Pemberdayaan Masyarakat Melalui Pelatihan Pembuatan Pupuk Kompos. J.Pengabdian Dan Pemberdayaan Masyarakat, 1(2).

Sulistyorini, L. (2005). Pengelolaan Sampah Dengan Cara Menjadikannya Kompos. J. Kesehatan Lingkungan, 2(1), 77-85.

Suprapto, P. K., Ali, M., \& Nuryadin, E. (2017). Program Pengenalan Dan Sosialisasi Penerapan Teknologi Olah Sampah Organik Rumah Tangga (Osama) Di Kampung Jati Kabupaten Ciamis. J. Pengabdian Siliwangi, 3(1), 180-186.

Widiyaningrum, P. 2015. Efektivitas Proses Pengomposan Sampah Daun Dengan Tiga Sumber Aktivator Berbeda. J.Rekayasa, 13(19), 107-11 